The Polish Journal of the Arts and Culture. New Series 9

(1/2019): 141-145 [REMARKS]

\title{
Some remarks about Betrayal. A new incarnation of Harold Pinter's play at the Harold Pinter Theatre in London
}

\section{Anna KuchtA}

Harold Pinter, one of the leading representatives of the theatre of the absurd, who is often bracketed with Samuel Beckett ${ }^{1}$, and a 2005 recipient of the Nobel Prize for Literature, successfully reveals in his works the impermanence of interpersonal relations, the conventions which govern social communication (which indeed turns out to be merely a game of appearances) and - perhaps above all - the loneliness of modern man. Pinter's protagonists are helpless, they experience a situation of unspecified menace (as in the case of his early plays, which were referred to by Irving Wardle as a comedy of menace ${ }^{2}$ ) or in the situation of entanglement in infelicitous and non-authentic relations from which one cannot extricate oneself, as in the case of Betrayal, the work which constitutes the focus of the present text.

From its inception in 1978 , this play saw numerous theatrical incarnations (not only in London, where it premiered, directed by Peter Hall in the National Theatre, but also in New York, Sydney, Hong Kong, Tel Aviv and Buenos Aires, which demonstrates the universality of the problems presented by the author), as well as a movie adaptation under the same title ${ }^{3}$, produced in 1983, starring Patricia Hodge (Emma), Jeremy Irons (Jerry) and Ben Kingsley (Robert). The most recent iteration of Betrayal, directed by Jamie Lloyd (which premiered on 13 March 2019) is produced by the London-based

${ }^{1}$ B. Dukore, The Theatre of Harold Pinter, p. 43.

2 I. Wardle, Comedy of Menace, pp. 28-33

3 Betrayal, directed by David Jones, United Kingdom 1983. This adaptation brought Pinter a nomination of the Academy Award in the category Best adapted screenplay (it was his second nomination; he was first nominated in 1981 for developing the screenplay of The French Lieutenant's Woman on the basis of John Fowles' novel). 
Harold Pinter Theatre, where the message of the author enjoys a particular presence 4 . In Lloyd's interpretation, Betrayal is characterised by an exceptional fondness for minimalism ("Spartan purity", according to Michael Billington's review for "The Guardian"), which at the same time allows what is most important to emerge, that is the fragile interpersonal relations and the mesh of falsehood which manifests itself in the statements of the protagonists. The limited scenography arranged by Soutra Gilmour (the only staple elements include three chairs whose changing arrangements conventionally suggest various kinds of spaces in which the subsequent scenes are played out), stage props, as well as the sober colour scheme of the play (both the scenery in which the amorous entanglements of the protagonists is presented and their clothes employ subdued, pastel colours, frequently akin to shades of grey) emphasise the dialogue layer of the text.

The vicissitudes of the chief protagonists of the work - Emma (played by Zawe Ashton), her husband, Robert (Tom Hiddleston) and Jerry, the friend of the house and at the same time Emma's lover (Charlie Cox) - are presented, according to the textual original, in reverse chronological order (the game of time - and especially of memory - is after all a recurrent theme in Pinter's works). The scene which opens the work is set in 1977, at a time when Emma's and Jerry's once passionate affair is over, leaving the protagonists with merely bitter-sweet memories, to which they return consumed by half-nostalgia, half-irony:

EMMA: I thought of you the other day.

JERRY: Good God. Why? ${ }^{6}$

Further encounters with the protagonists involve a gradual immersion into the past ("Well, it's nice, sometimes, to think back. Isn't it?" in the first conversation), until 1968, in which the affair began. The audience gets a glimpse of the convoluted history of the three protagonists by a series of short flashbacks. Therefore, the tension which is inherent in the drama, is not associated with the development of the plot in a chronological order (moreover, the plot was limited by the author - and by the director - to

4 Harold Pinter has London theatre named after him, [www 01].

$5 \mathrm{M}$. Billington, Betrayal review - Hiddleston is superb in haunting drama of deception, [www 02].

6 H. Pinter, Betrayal, p. 9.

7 Ibidem. 
a necessary minimum, the dilemmas of the protagonists being encapsulated in words), but it is associated with the audience prying into the secret-laden private lives of the protagonists, their understatements, lies and the games they play. Similarly as in many other works, in Betrayal too does Pinter explore and reveal that which is ordinary, mundane, apparently even banal, though in the end revealing the drama of human existence. Moreover, the temporal inversion prevents the reader from observing the development of the plot on the basis of cause and effect (the reader knows the ending before the beginning is revealed to him); nor can we evaluate the evolution of the characters of the protagonists, but observe the drama of the banal that happens within the four walls of prosaic mundaneness.

The eponymous betrayal, even though it is associated above all with Emma and Jerry, who cheat on their spouses (it is worth mentioning that these themes were inspired by the author's autobiographical experience ${ }^{8}$ ), essentially unfolds on many levels within the work:

EMMA: You know what I found out... last night? He's betrayed me for years. He's had... other women for years.

JERRY: No? Good Lord.

Pause.

But we betrayed him for years.

EMMA: And he betrayed me for years. ${ }^{9}$

The protagonists are tangled in a mesh of lesser and greater instances of falsehood and betrayal which merely intensify the tangle of their vicissitudes - all of them cheat and at the same time all of them feel cheated, and their frustrated hopes and unbridled emotions reveal themselves both in ironic dialogues and in their performances (the scene of the apparently ordinary dinner attended by Jerry and Robert, during which Robert - Hiddleston's role - suppresses the emotions associated with the discovery of his wife's affair by dealing with the meal that was served to him in an aggressive manner, is a perfect example). This tangle of the vicissitudes is presented by the director at the visual level by opting for silent participation of the third protagonist during the scenes which take place between the other two. Even

8 Cf. M. Billington, Harold Pinter.

9 H. Pinter, Betrayal, p. 17. 
though in Pinter's play the bulk of the dialogue is associated with two characters in various configurations (Emma and Robert, Emma and Jerry, Jerry and Robert), in Lloyd's iteration, the third person, although not an active participant in the dialogue at a given moment (albeit, in a way, the subject thereof), remains on the stage (as a silent, motionless shadow or a pang of conscience), representing a presence which refuses to be discarded from the memories of the protagonists (in the previously mentioned dinner scene of Jerry and Robert, Emma, played by Ashton - occupies a place in the background, eating an apple alone).

The performance engraves itself in the memory of the audience - the problems which are described by Pinter and which are presented by Lloyd turn out to be universal and still topical, and Ashton, Hiddleston and Cox engage in a perfect interplay of character, imbuing the almost classical drama of the four walls with life, ensuring the experience of genuine emotions on the part of the audience.

\section{Bibliography}

1. Billington M., Harold Pinter, Faber and Faber, London 2007.

2. Dukore B., The Theatre of Harold Pinter, "The Tulane Drama Review" 6 (3/1962), pp. 43-54.

3. Pinter H., Betrayal, Faber and Faber, London 2013 (ebook edition).

4. Wardle I., Comedy of Menace, "Encore" 5/1958, pp. 28-33.

\section{Filmography}

5. Betrayal, directed by David Jones, United Kingdom 1983.

\section{Internet sources}

[www 01] https://www.bbc.co.uk/news/entertainment-arts-14827867 [www 02] https://www.theguardian.com/stage/2019/mar/14/betrayalreview-a-haunting-reminder-of-deceptions-impact 


\section{Note about the author}

Anna Kuchta PhD. Graduate of the Centre for Comparative Studies of Civilizations (Jagiellonian University), recipient of The Ryoichi Sasakawa Young Leaders Fellowship (Kobe University). Her research interests include postmemory, trauma and tracing relations between literature and culture. She is a Member of "Maska" Magazine (ISSN 1898-5947) and "The Polish Journal of Aesthetics" (eISSN 2544-8242) editorial boards.

E-MAIL: anna.kuchta@uj.edu.pl 